Jurnal Keperawatan Silampari

Volume 4, Nomor 2, Juni 2021

e-ISSN: 2581-1975

p-ISSN: 2597-7482

DOI: https://doi.org/10.31539/jks.v4i2.1915

\title{
MODEL KEPERAWATAN KELUARGA PEKA BUDAYA SUNDA DALAM MENINGKATKAN PENGETAHUAN KELUARGA DAN MENURUNKAN KADAR GULA DARAH PADA DIABETISI LANSIA
}

\author{
Siti Badriah \\ Politeknik Kesehatan Kementerian Kesehatan Tasikmalaya \\ siti.badriah@dosen.poltekkestasikmalaya.ac.id
}

\begin{abstract}
ABSTRAK
Penelitian ini bertujuan untuk mengetahui efektifitas model keperawatan keluarga peka budaya sunda dalam meningkatkan pengetahuan keluarga dan menurunkan kadar gula darah pada diabetisi lansia. Desain penelitian yang digunakan dalam penelitian ini adalah quasi eksperimen pre dan post test. Hasil penelitian menunjukkan adanya peningkatan rerata pengetahuan keluarga dan kadar gula darah diabetisi lansia pada kelompok intervensi lebih tinggi dibanding dengan kelompok kontrol dengan p value sebesar 0,000. Simpulan, model keperawatan keluarga peka budaya sunda dapat meningkatkan pengetahuan keluarga dalam merawat diabetisi lansia dan berdampak terhadap terkendalinya kadar gula darah setelah intervensi model.
\end{abstract}

Kata Kunci : Budaya Sunda, Diabetisi Lansia, Gula Darah, Pengetahuan

\section{ABSTRACT}

This study aims to determine the Sundanese culture-sensitive family nursing model's effectiveness in increasing family knowledge and reducing blood sugar levels in older people with diabetes. The research design used in this study was a quasi-experimental pre and post-test. The results showed an increase in the mean family knowledge and blood sugar levels of older people with diabetes in the intervention group was higher than the control group with a p-value of 0.000. In conclusion, the Sundanese culture-sensitive family nursing model can increase family knowledge in caring for older people with diabetes and impact controlling blood sugar levels after the model intervention.

Keywords: Sundanese Culture, Older People with Diabetes, Blood Sugar, Knowledge

\section{PENDAHULUAN}

Diabetes Mellitus merupakan penyakit kronis yang sebagian besar terjadi pada lansia. Hal ini sesuai dengan hasil penelitian Rashedi et al., (2019) bahwa rerata penyandang diabetes di Kerman, Iran adalah 69.82 tahun. Kenyataan yang sama disampaikan oleh Rachmawati et al., (2019) yang melaporkan bahwa rerata usia respoden lansia diabetes di Depok adalah usia 64 tahun. Fenomena ini selaras dengan Hasil Riset Kesehatan Dasar tahun 2018 yang menggambarkan bahwa prevalensi diabetes di Indonesia berdasarkan karakteristik usia 55-64 tahun adalah 6,3\%, 65-74 tahun sebesar 6,0\%, dan diatas 75 tahun berjumlah 3,3\%. (Kemenkes, 2018; Setyawati et al., 2020). Kenyataan ini menunjukan bahwa lansia merupakan kelompok yang sangat rentan 
mengalami diabetes dan apabila tidak dilakukan program intervensi sebagai upaya pengendalian penyakit DM dikhawatirkan akan terjadi peningkatan prevalensi dengan berbagai komplikasinya di masa yang akan datang.

Beberapa model intervensi untuk lansia dengan penyakit PTM termasuk lansia diabetes sudah pernah diteliti diantaranya oleh Yang et al., (2020) dengan model kunjungan kelompok di China terhadap lansia Diabetes. Maryam et al., (2018) dengan model intervensi dukungan keluarga terhadap lansia Hipetensi di komunitas. Riasmini et al., (2019) melalui model kelompok keluarga mandiri (KKM) yang mengintegrasikan kelompok swabantu dan kelompok pendukung untuk lansia. Berbagai pendekatan yang dilakukan tersebut lebih menekanakan pada sistem dukungan keluarga dan pemberdayaan masyarakat, sementara pelibatan keluarga sebagai primordial prevention dengan berbasis budaya dalam pengendalian gula darah belum banyak menjadi kajian.

Leininger \& McFarland (2018) dengan trancultural nursingnya menyebutkan beberapa aspek budaya dapat menjadi bahan kajian dalam upaya pemberian asuhan keperawatan. Sementara itu keluarga sebagai family centre nursing (FCN) memandang bahwa keluarga merupakan unit dasar dalam perawatan anggota keluarga dan menjadi bagian yang sangat berpotensi untuk membantu lansia dalam mengatasi masalah kesehatan, mengubah status kesehatan serta mendukung terhadap perubahan gaya hidup (Sahar et al., 2018). Oleh karena itu perawat komunitas harus bekerjasama dengan keluarga untuk mencapai keberhasilan dalam pemberian asuhan kepada anggota keluarga. Adanya interaksi yang intensif antara perawat, pelaku rawat dan lansia dengan pendekatan silih asah, silih asuh silih asih dapat meningkatkan pemahaman keluarga dalam mengenal masalah budaya atau kebiasaan yang lebih baik dalam merawat kesehatan diabetisi lansia di rumah.

Bentuk kerjasama antara perawat dan keluarga ini selaras dengan filosofi budaya Sunda silih asah, silih asuh, silih asih yaitu saling mengasah dengan mengembangkan kemampuan keluarga dalam merawat lansia DM, mengasuh dengan cara memberikan pendampingan pada keluarga selama merawat lansia di rumah, dan saling mengasihi dengan selalu memberikan dukungan terhadap keluarga (Rosidi, 2010). Berdasarkan hal tersebut nilai-nilai silih asah, silih asuh, silih asih menjadi fondasi dari model asuhan keperawatan keluarga budaya Sunda untuk meningkatkan pengetahuan dan mengendalikan gula darah pada diabetisi lansia.

Tasikmalaya merupakan salah satu kota di Provinsi Jawa Barat, Indonesia, yang memiliki kasus PTM sebesar 23.885 dengan 570 diantaranya adalah penyakit diabetes pada lansia (Dinkes Kota Tasikmalaya, 2016). Fenomena tersebut menunjukan apabila program pengendalian gula darah tidak komprehensif dan hanya terbatas pada penatalaksaan secara individu, tanpa melibatkan keluarga dikhawatirkan peningkatan kasus DM dengan berbagai komplikasi akan terus meningkat. Oleh karena itu diperlukan keterlibatan keluarga untuk merawat kesehatan diabetisi lansia di rumah.

Keluarga merupakan bagian yang sangat berpotensi untuk membantu lansia dalam mengatasi masalah kesehatannya melalui dukungan terhadap budaya atau kebiasaan pola hidup yang sehat. Namun demikian telah ditemukan fakta bahwa demi membuat orang tuanya senang beberapa keluarga pada masyarakat Sunda cenderung mengikuti dan membiarkan orang tuanya melakukan apapun sesuai keinginannya termasuk dalam kebiasaan makan yang dapat menyebabkan gula darahnya naik, karena menuruti keinginan orang tua merupakan sebuah kewajiban dalam pandangan agama dan budaya Sunda (Badriah \& Sahar, 2019). Hal ini sejalan dengan nilai budaya Sunda yang menempatkan orang tua pada nilai yang tinggi seperti tertuang dalam ungkapan indung 
tunggul rahayu bapa tangkal darajat (ibu sebagai sumber keselamatan dan bapak sumber kesuksesan).Tingginya nilai orang tua, telah menjadikan keluarga-keluarga pada masyarakat sunda cenderung memanjakan orang tua dan menuruti semua keinginan orang tua sebagai bentuk taat dan patuh terhadap orang tua (Badriah et al., 2019). Berdasarkan hal tersebut apabila terus dibiarkan dikhawatirkan akan berdampak pada resiko peningkatan komplikasi diabetes akibat gula darah yang tidak terkendali.

Perubahan pandangan terhadap fenomena yang terjadi pada budaya Sunda sangat diperlukan melalui intervensi yang berbasis pada budaya yang sama. Pendekatan budaya sunda silih asah, silih asuh, silih asih dapat dilakukan oleh perawat terhadap keluarga dengan cara meningkatkan pengetahuan dalam manajemen perawatan DM pada lansia dengan menggunakan bahasa yang halus sesuai undak usuk dan tatakrama budaya sunda untuk melakukan negosiasi (mengubah) dan restrukturisasi (mengganti) pola kebiasaan yang tidak tepat. Berbagai penelitian terdahulu terkait budaya yang berpengaruh dalam merubah status kesehatan masyarakat dilakukan melalui komponen keyakinan terhadap kesehatan dan kolaborasi lintas sektoral (Kauh, 2020). Hasil penelitian yang sama dilporakan oleh Fuentes (2020) bahwa dalam menciptakan budaya baru yang mendukung kesehatan di era pandemi di Spanyol, khususnya bagi lansia dengan penyakit kronis maka kombinasi level intervensi baik sosial, kesehatan, pemerintah dan lembaga swasta berpengauh terhadap perbaikan status kesehatan lansia.

Penelitian tentang pendekatan budaya lokal atau kesukuan sudah pernah dilakukan, namun penelitian tersebut belum menjadi bahan kajian dalam upaya perbaikan status kesehatan mayarakat. Sedangkan, pada penelitian ini pendekatan budaya kesukuan dalam hal ini adalah budaya Sunda menjadi dasar pendekatan dalam memperbaiki status kesehatan lansia khsusnya dengan penyakit diabetes.

\section{METODE PENELITIAN}

Penelitian ini menggunakan desain quasi eksperimen dengan pendekatan pre-post test group design with control group dengan tujuan untuk melihat efektifitas atau pengaruh intervensi model keperawatan keluarga peka budaya sunda terhadap pengetahuan keluarga dan penurunan kadar gula darah pada diabetisi lansia yang akan dibandingkan dengan kelompok kontrol yang tidak mendapatkan intervensi model. Populasi pada penelitian ini adalah semua keluarga diabetisi lansia sebanyak 570 orang dengan perhitungan sampel menggunakan uji hipotesis beda dua mean, dengan kekuatan uji $\beta=90 \%$ dan $\alpha=5 \%$, koreksi drop out $10 \%$ didapatkan jumlah minimal 60 responden untuk kelompok intervensi dan 60 responden kelompok kontrol. Melalui teknik multistage random sampling dan simple random sampling maka ditetapkan kecamatan Cipedes untuk kelompok intervensi dan kecamatan Purbaratu untuk kelompok kontrol. Adapun kriteria inklusi untuk sampel dalam penelitian ini adalah anggota keluarga yang merawat diabetisi lansia dan tinggal bersama, dalam kondisi sehat, mampu membaca dan menulis, mampu berkomunikasi dengan baik, faham berbahasa Indonesia dan berbahasa sunda serta bersedia menjadi responden dengan memberikan persetujuan melalui inform consent.

Intervensi model keperawatan keluarga peka budaya diberikan dalam bentuk pelatihan terhadap keluarga diabetisi lansia pada kelompok intervensi tentang perencanaan makan, aktifitas fisik, pengendalian stres dengan teknik komunikasi yang sesuai dengan budaya sunda, dilanjutkan dengan kegiatan pendampingan berupa kunjungan rumah serta monitoring dan evaluasi terhadap keluarga dalam merawat diabetisi lansia di rumah. Selanjutnya baik kelompok intervensi maupun kelompok 
kontrol diberikan kuesioner pengetahuan pada 3 bulan dan 6 bulan setelah intervensi model. Analisis data menggunakan analisis univariat untuk karakteristik pelaku rawat dan lansia, bivariat dengan independent t-test dan multivariat dengan Uji General linier Model Repeated Measure (GLM-RM) untuk melihat perbedaan pada variabel yang diukur secara berulang pada perilaku merawat dan kadar gula darah.

Penelitian ini sudah mendapatkan persetujuan dari Komite Etik Fakultas Ilmu Keperawatan Universitas Indonesia dengan nomor 38/UN2.F12.D/HKP.02.04/2017 dan pelaksanaanya sudah memenuhi prinsip etik seperti diberikan penjelasan tentang tujuan penelitian dan menandatangani lembar persetujuan yang menandakan penerimaan responden untuk terlibat dalam penelitian, menjaga kerahasiaan responden, menyediakan waktu yang cukup leluasa saat pengambilan data dan pada saat kegiatan pelatihan berlangsung peneliti berusaha membuat suasana senyaman mungkin. Selain itu penelitian ini memberikan manfaat langsung pada keluarga yaitu meningkatkan pengetahuan dan untuk diabetisi lansia gula darah menjadi terkontrol. Penelitian ini juga menerapkan prinsip keadilan dengan memberikan perlakuan yang sama kepada responden dengan tidak membedakan jenis kelamin, suku, agama, baik sebelum, selama maupun setelah penelitian berakhir.

\section{HASIL PENELITIAN}

Tabel. 1

Analisis Perbedaan Pengetahuan Pelaku Rawat Sebelum dan Sesudah Intervensi Model pada Kelompok Intervensi dan Kelompok Kontrol $(\mathrm{n}=114)$

\begin{tabular}{|c|c|c|c|c|c|c|c|}
\hline & \multicolumn{3}{|c|}{$\begin{array}{l}\text { Kelompok Intervensi } \\
(\mathrm{n}=57)\end{array}$} & \multicolumn{3}{|c|}{$\begin{array}{l}\text { Kelompok Kontrol } \\
\quad(n=57)\end{array}$} & \multirow[b]{2}{*}{ Nilai $P$} \\
\hline & Mean & Median & $95 \% \mathrm{CI}$ & Mean & Median & $95 \% \mathrm{CI}$ & \\
\hline \multicolumn{8}{|l|}{ Pengetahuan } \\
\hline Sebelum & 35,8 & 33,3 & $31,3-40,3$ & 36,9 & 33,3 & $34,3-39,7$ & 0,658 \\
\hline Sesudah ( 3 bulan) & 65,9 & 66,7 & $62,7-69,1$ & 37,3 & 33,3 & $34,6-40,0$ & 0,000 \\
\hline \multirow[t]{2}{*}{ Sesudah ( 6 bulan) } & 77,9 & 80,0 & $74,7-81,1$ & 37,3 & 33,3 & $34,6-40,0$ & 0,000 \\
\hline & \multicolumn{3}{|c|}{$\mathrm{p}$ interaksi $=0,000$} & \multicolumn{3}{|c|}{ Partial Eta $(R)$ Squared $=0,399$} & \\
\hline
\end{tabular}

Pengetahuan sebelum intervensi dan 3 bulan setelah intervensi $(\mathrm{p}=0.000)$

Pengetahuan pada 3 bulan dan 6 bulan setelah intervensi $(\mathrm{p}=0.000)$

Berdasarkan tabel 1 terdapat perbedaan rerata nilai pengetahuan pelaku rawat antara kelompok kontrol dan kelompok intervensi terutama pada 3 bulan dan 6 bulan setelah intervensi model. Hasil uji statistik pada kelompok intervensi menunjukkan terdapat perbedaan yang signifikan pengetahuan antar pengukuran sesudah 3 bulan dan 6 bulan intervensi model (nilai $\mathrm{p}=0,000$ ). Hal ini dapat disimpulkan bahwa ada pengaruh intervensi model keperawatan keluarga peka budaya Sunda terhadap pengetahuan pelaku rawat terutama pada 3 bulan setelah intervensi model.

Tabel. 2

Analisis Perbedaan Kadar Gula Darah Diabetisi Lansia Sebelum dan Sesudah Intervensi Model pada Kelompok Intervensi dan Kontrol $(\mathrm{n}=114)$

\begin{tabular}{lccccccc}
\hline \multicolumn{1}{c}{ Variabel } & \multicolumn{3}{c}{ Kelompok Intervensi $(\mathrm{n}=57)$} & \multicolumn{5}{c}{ Kelompok Kontrol $(\mathrm{n}=57)$} & \\
\hline & Mean & Median & $95 \%$ CI & Mean & Median & $95 \%$ CI & Nilai p $^{*}$ \\
\hline Kadar gula darah & & & & & & & \\
Sebelum & 292, & 280 & $261,96-$ & 256. & 244 & $234.47-$ & 0.053 \\
& 96 & & 323,69 & 05 & & 277.04 & \\
\hline
\end{tabular}




\begin{tabular}{|c|c|c|c|c|c|c|c|}
\hline Sesudah ( 3 bulan) & $\begin{array}{c}216, \\
11\end{array}$ & 190 & $\begin{array}{c}190,34- \\
241,87\end{array}$ & $\begin{array}{c}258 . \\
28\end{array}$ & 224 & $\begin{array}{c}232.13- \\
284.44\end{array}$ & 0.000 \\
\hline \multirow{3}{*}{ Sesudah ( 6 bulan) } & 166,6 & 144 & $148,70-184,60$ & 273,6 & 273 & $249.67-$ & 0,000 \\
\hline & 5 & & & 7 & & 298.15 & \\
\hline & & intera & $=0,001$ & $\begin{array}{l}\text { Partial } \\
0,237\end{array}$ & $\overline{E t a}(R)$ & Squared & \\
\hline
\end{tabular}

Kadar gula darah sebelum intervensi dan 3 bulan setelah intervensi $(\mathrm{p}=0,000)$

Kadar gula darah pada 3 bulan dan 6 bulan setelah intervensi $(p=0,124)$

Berdasarkan tabel 2 menunjukkan terjadinya penurunan nilai rerata kadar gula darah antara sebelum terhadap 3 bulan sesudah penerapan model keperawatan keluarga peka budaya Sunda dengan (nilai $\mathrm{p}=0.000$ ) akan tetapi pada pengukuran 3 bulan terhadap 6 bulan sesudah intervensi tidak menunjukkan perbedaan yang signifikan (nilai $\mathrm{p}$ $=0.124)$. Namun demikian secara efek size, berdasarkan nilai mean tampak penurunan kadar gula darah sebesar 49,46 mg/dl pada 6 bulan setelah intervensi model. Berdasarkan hal tersebut dapat disimpulkan ada pengaruh intervensi model keperawatan keluarga peka budaya Sunda terhadap kadar gula darah terutama pada 3 bulan setelah intervensi model

\section{PEMBAHASAN}

Hasil penelitian menunjukkan adanya peningkatan pengetahuan secara signifikan pada 3 bulan dan 6 bulan sesudah intervensi. Hal tersebut sesuai dengan penelitian Yang et al.,(2020) yang menunjukkan adanya peningkatan rerata nilai pengetahuan dan manajemen diri yang lebih tinggi pada kelompok intervensi dibandingkan dengan kelompok kontrol ( $\mathrm{p}<0,05)$. Hasil yang sama dilaporkan Riasmini et al., (2019) bahwa terjadi peningkatan rerata pengetahuan pada 3 bulan dan 6 bulan sesudah intervensi model kelompok keluarga mandiri. Ketiga penelitian ini sama-sama mengalami peningkatan pengetahuan setelah diberikan pelatihan. Pengaruh Pelatihan atau pendidikan kesehatan terhadap peningkatan pengetahuan ini juga dibuktikan oleh Haryono et al., (2018) yang menunjukkan bahwa terdapat pengaruh yang signifikan antara pendidikan kesehatan terhadap peningkatan pengetahuan tentang diet, kadar gula darah sewaktu serta peningkatan kepatuhan diet pasien DM sebelum dan sesudah intervensi.

Upaya meningkatkan pengetahuan merupakan peran dari perawat komunitas, sesuai dengan yang disampaikan oleh Sahar, Setiawan dan Riasmini (2018) bahwa membantu klien dengan memberikan informasi merupakan peran perawat sebagai pendidik dan penasehat. Melalui model ini perawat komunitas dapat berperan memberikan pembelajaran pada keluarga dengan lansia DM berdasarkan pendekatan budaya Sunda silih asah, silih asuh, silih asih. Berdasarkan hal tersebut dengan peran dan fungsinya sebagai pendidik dan penasehat melalui pendekatan budaya, model ini terbukti telah mampu mengoptimalkan pengetahuan yang dimiliki oleh keluarga dalam merawat lansia DM.

Hasil uji menunjukkan adanya peningkatan rerata pengetahuan yang lebih tajam pada hasil pengukuran 3 bulan di bandingkan dengan 6 bulan setelah intervensi. Hal ini dimungkinkan karena adanya kegiatan pendampingan yang dilakukan 3 bulan pertama setelah pelatihan. Haviland et al., (2017) menjelaskan bahwa budaya itu bisa di share dan ditransmisikan melalui interaksi sosial sehingga para anggota budaya ikut terlibat dalam pertukaran informasi tentang nilai, norma dan kepercayaan yang mereka miliki. Lebih lanjut Leininger \& McFarland (2018) menyebutkan bahwa kebudayaan tidaklah diwariskan secara genetik, tetapi diperoleh manusia setelah kelahirannya melalui proses belajar dan mempelajari sesuatu. Berdasarkan hal tersebut adanya interaksi yang intensif antara perawat, pelaku rawat dan lansia dengan pendekatan silih asah, silih asuh silih asih 
dapat meningkatkan pemahaman keluarga dalam mengenal masalah budaya atau kebiasaan yang lebih baik dalam merawat kesehatan diabetisi lansia di rumah.

Perubahan rerata pengetahuan pelaku rawat sebelum terhadap 3 bulan setelah penerapan model di kelompok intervensi berbanding lurus dengan perubahan kadar gula darah pada diabetisi lansia dimana terjadi penurunan rerata nilai kadar gula darah sebesar $76,85 \mathrm{mg} / \mathrm{dl}$ sementara itu pada kelompok kontrol rerata kadar gula darah mengalami kenaikan sebesar 2,23 mg/dl. Hasil uji statistik menunjukkan adaya perbedaan yang signifikan kadar gula darah antara kelompok intervensi dan kelompok kontrol. Namun demikian kondisi ini tidak selaras dengan hasil penelitian Yang et al., (2020) yang menunjukan tidak ada perbedaan yang signifikan kadar gula darah antara sebelum dan setelah intervensi terkait manajemen perawatan DM dengan cara pemberian informasi melalui kunjungan rumah dalam model kunjungan rumah yang dilakukan secara berkelompok dengan anggota terdiri dari dokter, perawat, ahli gizi dan psikolog dengan nilai $\mathrm{HbA1c}(\mathrm{p}=0,272)$. Hal ini kemungkinan terjadi karena perbedaan parameter yang menjadi alat ukur pemeriksaan gula darah yang berbeda, dimana pada penelitian ini menggunakan parameter pemeriksaan kadar gula darah sewaktu. Selain itu pendekatan budaya silih asih dan silih asuh dalam bentuk pendampingan secara intensif pada penelitian ini memungkinkan keluarga dan diabetisi lansia merasa termonitor dan diperhatikan setiap saat sehingga berpengaruh terhadap kecenderungan untuk berperilaku positif untuk mendukung terhadap manajemen pengelolaan DM yang efektif dan berpengaruh terhadap penurunan kadar gula darah.

Pada beberapa budaya di Indonesia, seperti dilaporkan oleh Parinduri (2020) dalam penelitian etnografi melaporkan bahwa dalam budaya Toba nilai kekerabatan seperti berbakti pada orang tua, bersikap baik terhadap sesama merupakan bentuk dukungan yang bersumber dari budaya kesukuan yang sangat berperan dalam meningkatkan nilainilai positif dalam kehidupan bermasyarakat. Hal tersebut selaras dengan nilai budaya Sunda silih asah, silih asuh dan silih asih (saling mengasah, saling mengasuh dan saling mengasihi) sebagai bentuk dukungan anggota masyarakat Sunda terhadap sesama untuk menjamin kehidupan yang lebih baik dalam hal ini adalah kehidupan keluarga dengan diabetisi lansia. Berdasarkan hal tersebut interaksi yang efektif melalui proses pendampingan perawat dan kader dalam bingkai budaya Sunda (silih asah, silih asuh dan silih asih) efektif dalam mengendalikan kadar gula darah pada diabetisi lansia.

Selanjutnya hasil pengukuran pengetahuan dan tindakan pada pengukuran 3 bulan terhadap pengukuran 6 bulan setelah intervensi menunjukkan peningkatan yang relatif kecil. Menurut analisis peneliti walaupun kegiatan pendampingan pada kelompok intervensi sudah bersipat mandiri dalam arti tidak ada intervensi pemberian informasi secara berulang pada keluarga oleh perawat dalam bentuk kunjungan rumah, namun demikian selama masa penelitian, kegiatan Prolanis atau Program Pengelolaan Penyakit Kronis di Puskesmas yang salah satu kegiatannya adalah pemberian edukasi tentang penyakit DM dan perwatannya yang memungkinkan pelaku rawat maupun diabetisi lansia mampu mempertahankan pengetahuannya. bahkan masih memungkinkan mengalami peningkatan walaupun relatif hanya sedikit. Kondisi tersebut sejalan dengan perubahan kadar gula darah yang relatif lebih kecil dibandingkan dengan perubahan pada 3 bulan setelah intervensi model.

Hasil penelitian pada kelompok kontrol menunjukkan tidak terdapat selisih rerata nilai pengetahuan baik pada sebelum, 3 bulan maupun 6 bulan pengukuran. Hal ini dimungkinkan karena ketidakterpaparan informasi melalui pelatihan dan pendampingan. Normina (2017) menjelaskan bahwa dalam pandangan pendidikan dan kebudayaan 
pengetahuan yang didapat manusia tidak hanya didapat melalui transmisi pendidikan formal tapi juga melalui proses belajar dari interkasi dengan lingkungan sosialnya. Hal ini menunjukkan bahwa saling mengajari, saling mengasihi dan mengasuh (silih asah, silih asuh dan silih asih) merupakan nilai budaya yang dapat menjamin kehidupan masyarakat sunda menjadi yang lebih baik. Kondisi tersebut mencerminkan bahwa model keparawatan keluarga peka budaya Sunda melalui metode pelatihan yang dilanjutkan dengan pendampingan dapat meningkatkan pemahaman keluarga tentang perawatan diabetisi lansia menjadi lebih baik dan sebaliknya ketika hal tersebut tidak dilakukan maka pengetahuan keluarga tidak akan mengalami perubahan seperti yang ditemukan pada kelompok kontrol. Kenyataan ini telah berdampak pada tidak terkendalinya kadar gula darah kelompok kontrol baik pada 3 bulan maupun 6 bulan pengukuran.

Pada penelitian ini terdapat keterbatasan terutama dalam pemeriksaan kadar gula darah dilakukan secara terjadwal dengan jenis pemeriksaan gula darah sewaktu. Pemeriksaan gula darah sewaktu ini tidak menggambarkan pengontrolan kadar gula darah yang sebenarnya dan memungkinkan lansia diabetes melakukan upaya dengan cara memperketat makan dan minum yang tidak mengandung gula sebelum pemeriksaan dilakukan supaya hasil pemeriksaan kadar gula darahnya menunjukkan nilai yang normal.

\section{SIMPULAN}

Model keperawatan keluarga peka budaya Sunda terbukti efektif dalam meningkatkan pengetahuan keluarga dalam merawat diabetisi lansia dan berperan besar dalam menurunkan kadar gula darah yang berarti bahwa model keperawatan keluarga dengan pendekatan budaya silih asah, asuh dan asih telah berperan dalam memperbaiki kadar gula diabetisi lansia.

\section{SARAN}

Model keperawatan keluarga peka budaya ini dapat direplikasi dan dijadikan sebagai pola pendekatan dalam penanganan penderita dengan diabetes pada lansia. Selanjutnya bisa dilakukan penelitian dengan model yang sama tetapi dengan pengukuran kadar gula darah menggunakan parameter HbAlc

\section{DAFTAR PUSTAKA}

Badriah, S., Sahar, J., Gunawijaya, J., \& Prasetyo, S. (2019). Pampering Older People with Diabetes in Sundanese Culture: A Qualitative Study. Enfermeria Clinica, 29(Insc 2018), 733-738. https://doi.org/10.1016/j.enfcli.2019.04.111

Haryono, S., Suryati, E. S., \& Maryam, R. S. (2018). Pendidikan Kesehatan tentang Diet terhadap Kepatuhan Pasien Diabetes Mellitus. Jurnal Riset Kesehatan, 7(2), 91. https://doi.org/10.31983/jrk.v7i2.3308

Haviland, W. A., Prins, H. E. L., Walrath, D., \& McBride, B. (2017). Culutal Anthropology. The Human Challenge. Journal of Chemical Information and Modeling. https://doi.org/10.1017/CBO9781107415324.004

Kauh, T. J. (2020). Building a Culture of Health Through Research: The Role of the Physical Activity Research Center. Preventive Medicine, 130(November 2019), 105894. https://doi.org/10.1016/j.ypmed.2019.105894

Kemenkes. (2018). Hasil Utama Riskesdas 2018

Leininger, M., \& McFarland, M. R. (2018). Transcultural Nursing: Concepts, Theories, Research, and Practice (3rd ed). McGraw-Hill Education / Medical 
Maryam, R. S., Resnayati, Y., Riasmini, N. M., \& Mambang Sari, C. W. (2018). Effect of Family Support Intervention Towards Quality of Life with Elderly's Hypertension in Community. Jurnal Keperawatan Padjadjaran, 6(3), 281-288. https://doi.org/10.24198/jkp.v6i3.670

Normina, N. (2017). Pendidikan dalam Kebudayaan. Ittihad Jurnal Kopertais Wilayah XI Kalimantan, 15(28), 17-28

Parinduri, M. A. (2020). Pendidikan Akhlak dalam Perspektif Budaya Batak Toba : Studi pada Masyarakat Muslim di Tapanuli Utara Moral Education Within the Perspective of Batak Toba Culture : A Case Study Of Muslim Community. Jurnal Sosial Budaya dan Keislaman, 22(3), 1-13. https://doi.org/10.14203/jmb.v22i3.1075

Rachmawati, U., Sahar, J., \& Wati, D. N. K. (2019). The Association of Diabetes Literacy with Self-Management among Older People with Type 2 Diabetes Mellitus: a Cross-Sectional Study. BMC Nursing, 18(S1), 34. https://doi.org/10.1186/s12912019-0354-y

Rashedi, V., Iranpour, A., Mohseni, M., \& Borhaninejad, V. (2019). Risk Factors for Fall in Elderly with Diabetes Mellitus Type 2. Diabetes \& Metabolic Syndrome: Clinical Research \& Reviews, 13(4), 2347-2351. https://doi.org/10.1016/j.dsx.2019.06.001

Riasmini, N. M., Sahar, J., Supartini, Y., \& Maryam, R. S. (2019). Independent Family Group Model Improving Health Status and Quality of Life of Elderlyin the Community. Indian Journal of Public Health Research \& Development, 10(12), 1930. https://doi.org/10.37506/v10/i12/2019/ijphrd/192152

Rosidi, A. (2010). Mencari Sosok Manusia Sunda. Pustaka jaya

Sahar, J, Setiawan, A, Riasmini, N, M, N. \& M. E. (2018). Keperawatan Kesehatan Komunitas dan Keluarga (1 st Indon). Elsevier Pte Ltd

Setyawati, A., Ngo, T., Padila, P., \& Andri, J. (2020). Obesity and Heredity for Diabetes Mellitus among Elderly. JOSING: Journal of Nursing and Health, 1(1), 26-31. https://doi.org/https://doi.org/10.31539/josing.vli1.1149

Vicente, F. (2020). Social and Health Care Coordination: Towards a New Culture of Care. Enfermería Clínica (English Edition), 30(5), 291-294. https://doi.org/10.1016/j.enfcle.2020.09.001

Yang, L., Li, L., Cui, D., Wu, Y., Qiu, L., Qin, J., \& Zhu, X. (2020). Effectiveness of Group Visits for Elderly Patients with Type 2 Diabetes in an Urban Community in China. Geriatric Nursing, 41(3), 229-235. https://doi.org/10.1016/j.gerinurse.2019.10.001 